\title{
Novas religiões japonesas na periferia urbana O "Johrei Center" da Igreja Messiânica Mundial (IMM) do bairro São João de Guarulhos/SP
}

\author{
Renan Lescano Romão* \\ Paulo Barrera Rivera**
}

\section{Resumo}

O presente artigo estuda um "Johrei Center" da IMM localizada na periferia urbana do Município de Guarulhos, na cidade de São Paulo. Trata-se do Johrei Center, do bairro São João. Foca-se a atenção nas interações entre os seguidores da IMM e o bairro em condições de vulnerabilidade social. Estuda-se a forma como o Johrei Center e os próprios fiéis entendem o seu papel em relação ao seu entorno social. A pesquisa utiliza diversos dados e informação colhidos em observação de campo das atividades do grupo religioso, em entrevistas e em questionários aplicados aos seguidores.

Palavras-chave: Novas Religiões Japonesas. Periferia urbana. Igreja messiânica mundial. Vulnerabilidade social.

\section{New japanese religions in the urban periphery The "Johrei Center" of the World Messianic Church (WMC) in district of São João, Guarulhos/SP}

\begin{abstract}
This article studies one "Johrei Center" of the World Messianic Church (WMC) located in the urban periphery of the Municipality of Guarulhos, in São Paulo city. This is the Johrei Center, in the neighborhood of São João. The article pays attention on the interactions between the followers of WMC and the neighborhood in social and economic conditions of social vulnerability. We study how the Johrei Center and the faithful themselves understand their role in relation to their social environment.
\end{abstract}

\footnotetext{
* Psicólogo, Mestre em Ciências da Religião e doutorando em Ciências da Religião pela UMESP.

** Doutor em Ciências da Religião e Professor da pós-graduação em Ciências da Religião da Universidade Metodista de São Paulo.
} 
The research uses various data and information collected in field observation of the activities of the religious group, in interviews and questionnaires applied to followers. Keywords: New Japanese Religions. Urban outskirts. World messianic church. Social vulnerability.

\section{Nuevas religiones japonesas en la periferia urbana El "Johrei Center" de la Iglesia Mesiánica Mundial (IMM) del barrio São João de Guarulhos/SP}

\section{Resumen}

El presente artículo estudia un "Johrei Center" de la Iglesia Mesiánica Mundial (IMM) ubicada en la periferia urbana del municipio de Guarulhos, en la ciudad de São Paulo. Se trata del Johrei Center, del bairro de São João. Se presta atención a las interacciones entre los seguidores de la IMM y el barrio en las condiciones sociales y económicas de vulnerabilidad social. Se estudia la forma como el Johrei Center y sus propios fieles comprenden su papel en relación a su entorno social. La investigación utiliza diversos datos e informaciones recogidos en observación de campo de las actividades del grupo religioso, en entrevistas y en cuestionarios aplicados a los seguidores.

Palabras clave: Nuevas Religiones Japonesas. Periferia urbana. Iglesia mesiánica mundial. Vulnerabilidad social.

\section{Introdução}

O estudo das religiões nas periferias urbanas remete, necessariamente, a prestar atenção ao contexto maior do processo de industrialização e a consequente marginalização e urbanização. O Johrei Center aqui estudado ${ }^{1}$ está localizado num bairro da periferia urbana, produto da industrialização intensa e urbanização acelerada do Município de Guarulhos. A primeira parte do artigo é dedicada a reconstruir esse pano de fundo. Passa então a determinar o lugar das Novas Religiões Japonesas (NRJ) na periferia urbana do Brasil, e na sequência apresenta-se o bairro São João e a constituição do campo religioso guarulhense. A segunda parte do artigo é dedicada a analisar a interação dos membros do Johrei Center com o entorno social em que ele se encontra. A análise leva em consideração as caraterísticas do bairro em questão, o perfil social e econômico dos atores religiosos e as práticas religiosas dos fiéis. Analisam-se, finalmente, de acordo com a opinião dos próprios seguidores da IMM, qual é a contribuição do Johrei Center ao próprio bairro em condição de periferia, como acontece o processo

Cabe destacar que o artigo aqui apresentado decorre de uma pesquisa mais ampla sobre a IMM na periferia urbana desenvolvida entre os anos de 2016 e 2018 junto ao Grupo de Pesquisa REPAL, e que resultou na dissertação Romão (2018). 
de construção da identidade dos seguidores com o grupo religioso, e a criatividade dos fiéis, outorgando sentidos às diversas práticas religiosas para além das expectativas da instituição religiosa.

\section{Industrialização e marginalidade urbana em Guarulhos}

O município de Guarulhos, a segunda mais populosa cidade do Estado de São Paulo, configurou-se como importante centro econômico e industrial e sua proximidade com a capital paulista levou a acolher o seu transbordamento populacional. A expansão de sua periferia urbana foi rápida e se tornou uma saída para a lotação dos trabalhadores, fenômeno comum a outras cidades, especialmente de Regiões Metropolitanas, no processo de industrialização da segunda metade do século XX dos municípios no Brasil (GAMA, 2009). Durante a década de 1940, chegaram ao município as primeiras indústrias dos setores metalúrgico, elétrico, plástico, alimentício e de peças para automóveis levando à aprovação de planos de arruamentos e loteamentos que dessem alguma infraestrutura para tal crescimento por parte da Câmara Municipal. A intenção não era exatamente proporcionar melhores condições aos moradores.

Nesse contexto de desenvolvimento industrial e urbano, iniciou-se a construção de grandes rodovias (Dutra e Fernão Dias) que atendiam à região guarulhense, e as leis de incentivo fiscal foram renovadas em 1948. O loteamento periférico, como porta de acesso à casa própria dos trabalhadores mais pobres, migrantes em maioria, tornou-se parte do ideal operário à época (CAMPOS FILHO, 1999). Os loteamentos, porém, eram muitas vezes isolados e precários, uma solução bastante improvisada que beneficiava muito mais os ricos donos dos lotes. Onde antes, em Guarulhos, predominavam chácaras, olarias e portos de extração de areia, passaram a figurar moradores desprovidos de qualquer infraestrutura como ruas pavimentadas, esgoto, água e transporte público. É nesse contexto de marginalidade, quanto à atenção dos aparelhos públicos, que se dá ao lado e como produto da industrialização, que surgem os contornos da periferia desse município. A curva de crescimento populacional (Gráfico 1) aproxima-se de um exponencial. 
Gráfico 1 - Crescimento populacional de Guarulhos.

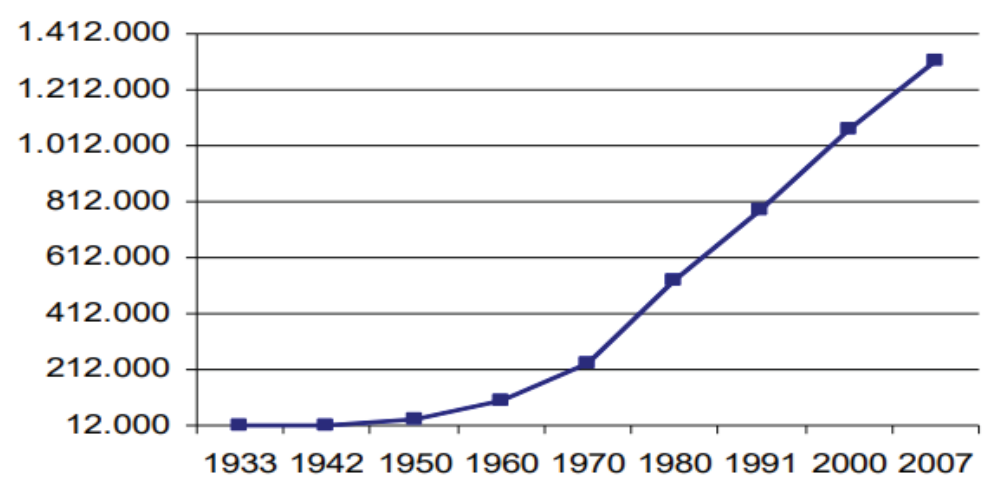

Fonte: Prefeitura Municipal de Guarulhos, 2011.

Nas décadas de 1950 e 1960, os vetores de crescimento populacional seguem na direção onde a terra era mais barata, nas franjas de proteção ambiental. O município se tornou definitivamente uma opção para localização industrial, com a consequente chegada de grande contingente de mão de obra que passou a ocupar esses loteamentos, especialmente das atuais regiões dos bairros de Cumbica, Lavras, Bonsucesso e Taboão. Ocorreu, assim, um crescimento demográfico vertiginoso e desordenado entre a década de 1950 até a década de 1990 (GUARULHOS, 2011).

Gráfico 2 - Urbanização de Guarulhos (2010).

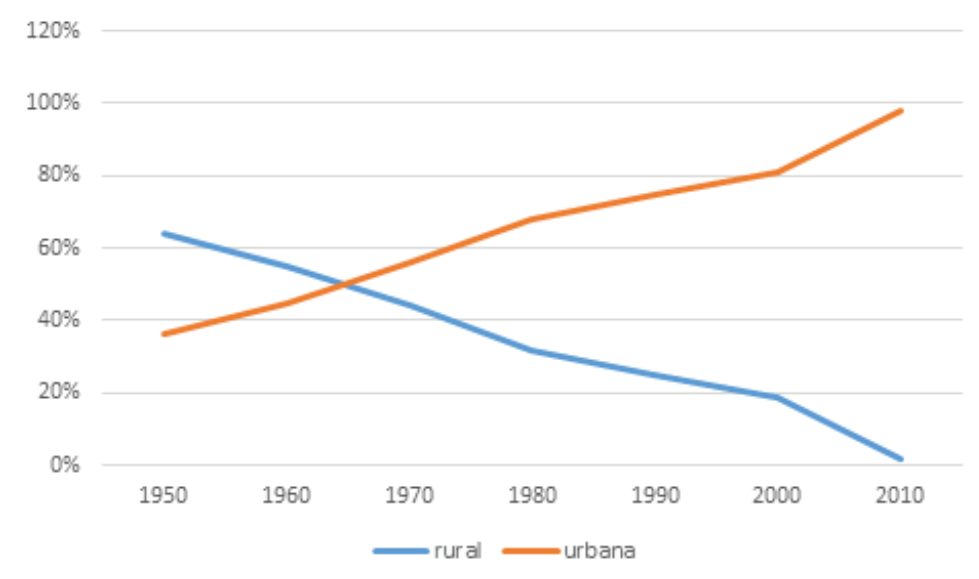

Fonte: IBGE, Censo 2010. 
A urbanização que, na década de 1980, já girava em torno de $80 \%$ da cidade, cresce para aproximadamente $98 \%$ no ano 2009 , sendo que sua população foi quintuplicada em relação à década de 1950 (IBGE, Censo 2010).

O município de Guarulhos possui um IDHM de 0,763, em 2010, classificando-o entre os municípios com faixa de Desenvolvimento Humano Alto (IDHM entre 0,700 e 0,799$){ }^{2}$ Mas, ao se observar o indicador favorável de renda, por exemplo, nota-se que o maior índice de concentração dessa renda no município está ainda ligado às regiões de maior concentração industrial. Aqui percebemos que o espaço urbano vai se configurando de modo a privilegiar as áreas industriais às áreas de vulnerabilidade, que requerem atenção à população, como sugerido por Castells (1983). Apesar da importante expressão econômica dessas regiões no município, fruto da produção industrial, a mesma parece não se converter em melhorias sociais para a população do entorno imediato. Tendo em vista esse descompasso, fica evidente que nesses bairros de Guarulhos a riqueza trazida pela indústria é mais uma marca de aprofundamento das diferenças sociais, que podem ser constatadas ao compararmos com o índice de vulnerabilidade dessas mesmas regiões do município e notarmos a alta vulnerabilidade que concorre no mesmo espaço. O menor nível de vulnerabilidade do município está concentrado na região sudoeste, na qual primeiro se instalaram aparelhos públicos, comércios e onde hoje estão os bairros mais ricos. Os maiores índices de vulnerabilidade se distribuem em diversos núcleos, com destaque ao do entorno da região do Aeroporto de Guarulhos e o núcleo leste, que faz fronteira com o município de Arujá (GUARULHOS, 2000).

Quando comparados os grupos de vulnerabilidade no município, temos a seguinte composição: 1,6\% da população pertence ao grupo de baixíssima vulnerabilidade, $28,5 \%$ ao grupo de muito baixa vulnerabilidade, $21,6 \%$ ao grupo de baixa vulnerabilidade, $19,5 \%$ pertencem ao grupo de média vulnerabilidade, $15,1 \%$ ao grupo de vulnerabilidade alta e $13,7 \%$ ao grupo de vulnerabilidade muito alta. Assim, somando-se os grupos de média, alta e muito alta vulnerabilidade se obtém $48,3 \%$ da população de Guarulhos que se encontra em situação vulnerável.

Comparando os grupos de média vulnerabilidade (19,5\% da população), alta vulnerabilidade $(15,1 \%$ da população) e altíssima vulnerabilidade (13,7\% da população) observa-se que quanto mais vulnerável tanto maior a

2 PNUD, Ipea e FJP. Disponível em: http://www.atlasbrasil.org.br/2013/pt/perfil m/ guarulhos sp. 
probabilidade de viver com meio salário mínimo per capita (25,3\%, 27,8\% e $39,2 \%$, respectivamente), bem como, tanto maior a tendência de mulheres com menos de 30 anos de idade serem as chefes de família (9,9\%, 19,1\% e $22,6 \%$, respectivamente). O que esses dados indicam coletivamente é que a cidade de Guarulhos, quando comparada às demais 16 cidades brasileiras de população superior a 1 milhão de habitantes, está entre as três cidades que mais reduziram o percentual do Índice de Vulnerabilidade Social (IVS) entre os anos de 2000 e 2010. A queda do município é de 24,39\%, ou seja, de um índice global de 0,41 para 0,31, nesse período, sendo agora atribuído o nível de vulnerabilidade média. Mas, o Índice Paulista de Vulnerabilidade Social (IPVS) mostra os desequilíbrios sociais e econômicos do município.

Figura 1 - Mapa - Índice Paulista de Vulnerabilidade Social - Município de Guarulhos (2000).

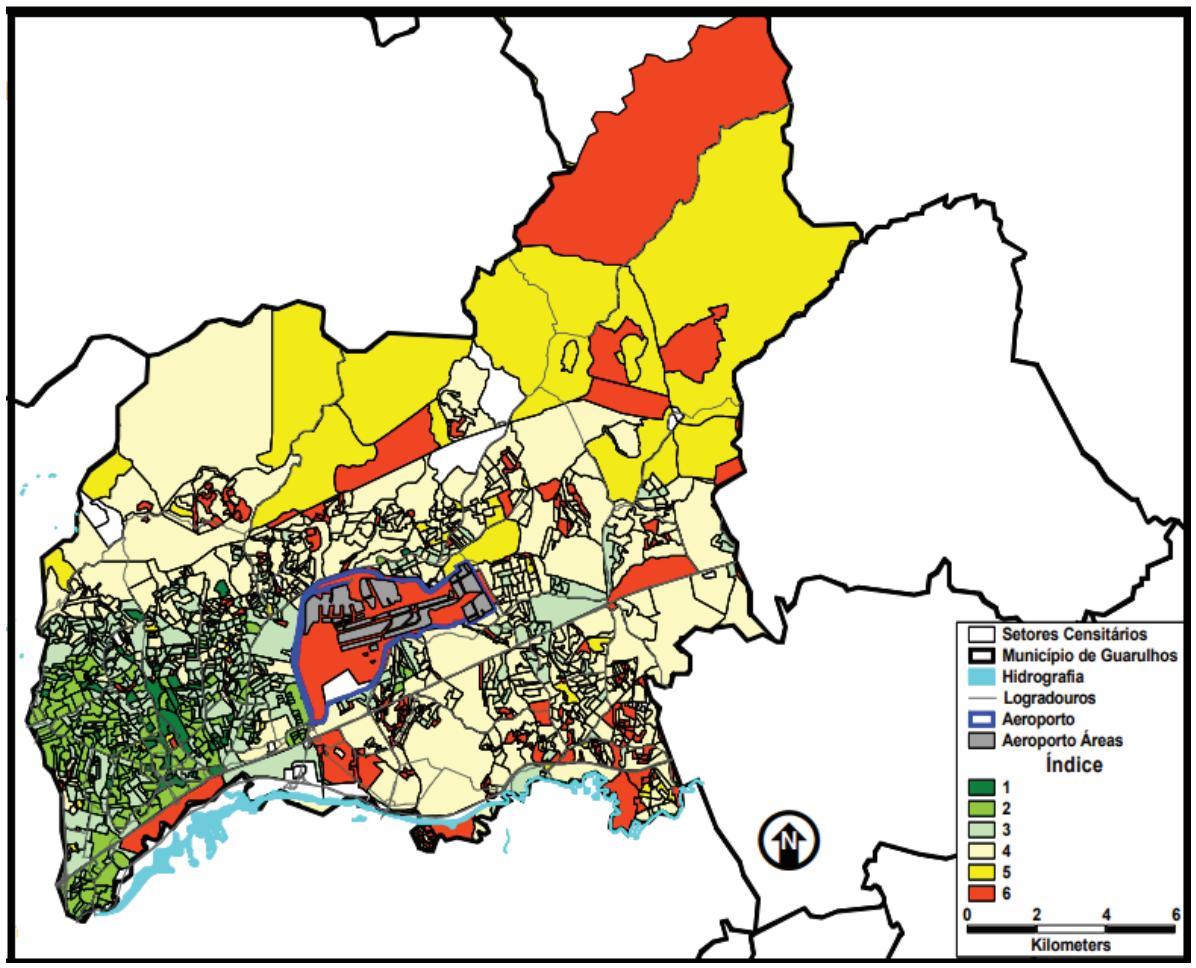

Fonte: IBGE. Censo Demográfico 2000. Fundação Seade. 
No índice paulista de vulnerabilidade social, que possui uma classificação crescente de baixíssima vulnerabilidade, relacionada à nota 1 , até a altíssima vulnerabilidade, relacionada à nota 6 , nota-se a concentração dos índices mais baixos e, por conseguinte, de menor vulnerabilidade, na região sudoeste de Guarulhos - nos bairros mais abastados e próximos à região do centro, fazendo fronteira com o município de São Paulo. Para além dessa porção de concentração, a maioria do território recai em índices equivalentes às notas de 4 a 6 de vulnerabilidade social, desde o entorno da região do aeroporto até as regiões mais a norte e mais a oeste do município.

Esse dado confirma que a distribuição desigual dos aparelhos públicos ocorre privilegiando regiões específicas. Os altos índices de vulnerabilidade criam carências sociais, econômicas e culturais que são contornadas por meio de inovações por parte das populações que ali vivem, e a religião é um espaço privilegiado dessas inovações.

\section{As NRJ nas periferias urbanas no Brasil}

É no complexo de carências e produções próprias da periferia urbana que as religiões e toda a sua rede revelam espaços privilegiados de construção de sentido. Nas periferias urbanas brasileiras, em especial do Rio de Janeiro e de São Paulo, destaca-se a presença dos católicos e dos evangélicos, sendo que estes despontaram numericamente nas últimas décadas, especialmente entre as classes mais pobres. No contexto de periferia, o pentecostalismo é a vertente religiosa que se sobressai e uma grande diversidade de igrejas surge como opções aos indivíduos. Nesse âmbito de vulnerabilidades, pesquisas demonstram que a religião se revela atuando como instrumento de enfrentamento do preconceito racial por parte dos adeptos, como veículo do ativismo e na contribuição de formação de redes solidárias em contextos de expressiva vulnerabilidade (RIVERA, 2010; NORONHA, 2016). "Migração e redes religiosas na periferia do Grande $\mathrm{ABC}$ : diversos olhares para uma crise urbana." In: Rivera (Org.) Diversidade religiosa e laicidade no mundo urbano Latino-americano, Curitiba, CRV (2016).

Diante de tamanha pluralidade religiosa presente na periferia, cresce o trânsito religioso: muitos aderem e abandonam igrejas, e aumenta ainda o número dos sem religião. Observa-se que aquelas igrejas pentecostais mais organizadas e hierarquizadas, por exemplo, não possuem tanta penetração como as pequenas igrejas pouquíssimo hierarquizadas, mas tão abundantes 
em regiões como as favelas. Do ponto de vista da classe social, os dados revelam que a classe $\mathrm{E}$ é destaque como a menos religiosa de todas, sendo que $7,72 \%$ desses sujeitos se declaram sem religião, já o catolicismo desponta ainda como a religião representante de cerca de $72,76 \%$ desta. Quanto aos evangélicos pentecostais, que muito despertaram interesse nas pesquisas acerca das dinâmicas religiosas no país nos últimos anos, verificou-se que estão concentrados no nível intermediário inferior de distribuição de renda, ou seja, cerca de 15,34\% na classe D (NERI, 2011).

A classe $A B$ é majoritariamente católica, seguida de 5,52\% que se declaram espiritualistas. Quanto ao catolicismo parece, portanto, predominante ainda nas pontas das classes sociais, ou seja, nas mais abastadas e nas mais pobres. Quanto à taxa de adesão a outras religiões, verifica-se que esta cai de $9,25 \%$ na classe $A B$ para $2,24 \%$ na classe $E$, o que sugere fatores que dificultam, de modo geral, o acesso a uma religião alternativa por aqueles com menor renda - fato reforçado pelo fator escolaridade, que revela que $10,23 \%$ dos que possuem mais de 12 anos de estudo são aqueles que aderem a essas religiosidades alternativas à matriz cristã hegemônica em nosso país. Provavelmente, esse fator de escolaridade exerce influência na conversão das religiões que demandam do novo adepto um aprendizado, incluindo o estudo formal e sistemático de suas doutrinas, por exemplo, por meio da leitura de livros e materiais de formação. Ao tratar da periferia de São Paulo, observa-se uma taxa de 61,26\% de católicos, 16,19\% de evangélicos pentecostais, 9,17\% de outros evangélicos, seguidos de $8,57 \%$ de pessoas que se declaram sem religião, e apenas $1,79 \%$ de espíritas e $0,16 \%$ de adeptos de religiões afrobrasileiras (NERI, 2011).

As Novas Religiões Japonesas (NRJ) representam uma parcela minoritária no quadro religioso plural brasileiro, figurando no Censo do IBGE entre as religiões de uma categoria mais genérica chamada de "novas religiões orientais", que incluem não apenas os novos movimentos religiosos japoneses, mas outros de origem oriental, como os indianos "Hare-Krishna" e os tibetanos, butaneses e nepaleses do "Budismo Tibetano", por exemplo.

Esse fator dificulta a identificação exclusiva de crescimento e decréscimo das populações religiosas das NRJ para além dos dados censitários próprios das instituições, ao menos quando tratamos de religiões menores como a Oomoto, Tenrikyo e Konko. Aquelas NRJ que se destacaram numericamente, porém, puderam ser percebidas fora do grande grupo de religiões orientais. No censo de 2010, nota-se o crescimento de algumas destas 
NRJ, como a Soka Gakkai, a Seicho-No-Ie e a Igreja Messiânica Mundial, relacionado, em grande parte, à popularização das mesmas fora do eixo de nipo-descendentes, de onde provinha o seu grande público até então.

No quadro nacional, onde as novas religiões orientais representam apenas $0,09 \%$ da população brasileira total, ao tratar-se do aspecto "classe", observa-se que estas não possuem representatividade na classe "E", sendo que a representatividade cresce de $0,02 \%$ da classe "D" para $0,12 \%$ na classe "C" e mais que dobra (para 0,27\%) na classe "AB". Esses dados revelam que existe uma tendência entre as novas religiões orientais em relação à classe social, tendência essa de maior popularidade dessa matriz religiosa entre as classes sociais mais ricas (NERI, 2011).

Quanto às periferias urbanas que mais possuem representantes das religiões orientais e asiáticas, observam-se a de Porto Alegre $(0,77 \%)$, de Curitiba $(0,42 \%)$ e de São Paulo $(0,41 \%)$. Ao tratar das capitais com maior adesão a religiões orientais e asiáticas temos São Paulo $(1,4 \%)$, seguido de Rio de Janeiro (1,03\%) e Porto Alegre (0,79\%). Esses dados parecem indicar que não necessariamente onde há maior representatividade dessas religiões na população total haverá reflexo proporcional na representatividade nas periferias, tendo em vista que São Paulo possui a maior população de adeptos de religiões orientais, mas é a terceira em representatividade de penetração na periferia. Ainda se nota que a migração de orientais para algumas regiões do país já foi superada como influência numérica nos adeptos de religiões orientais, pois, tanto a segunda (Rio de Janeiro) quanto a terceira capital (Porto Alegre), não estão vinculadas a destinos tradicionais desses imigrantes (NERI, 2011).

\section{Caracterização do bairro São João}

O Johrei Center objeto de atenção neste artigo encontra-se no bairro São João. O poder público dividiu os grupamentos de bairros em Unidades de Planejamento Regional (UPR). O bairro São João, que pertence ao núcleo do entorno do Aeroporto, formado por bairros com índices altos de vulnerabilidade, foi caracterizado predominantemente pelos loteamentos irregulares (também conhecidos como invasões), posteriormente regularizados, e loteamentos periféricos. Pertencente à UPR São João, que inclui ainda os bairros do Bananal, Lavras e Fortaleza, teve seu crescimento populacional mais expressivo nos anos 1990, como consequência posterior à instalação do aeroporto na região, tratando-se de uma das regiões mais precárias do 
município, com predominância de renda entre 3 a 5 salários mínimos entre seus moradores, a região ainda possui Índice de Exclusão Social (IES) negativos em todos os aspectos.

A ocupação do bairro São João remonta à década de 1960, e hoje é uma região altamente urbanizada, contando com comércios, escolas municipais e estaduais, todos sendo atendidos na área da saúde pela Unidade Básica de Saúde Cidade Serôdio e pela Unidade de Pronto Atendimento São JoãoLavras. Conta ainda com o terminal urbano de ônibus.

Quando analisados os dados fornecidos pela prefeitura municipal de Guarulhos no ano de 2000, visando abordar o referencial de "autonomia" do Índice de Exclusão Social das famílias que moram no bairro, observa-se que este gira em torno de - 0,62, o segundo pior dos oito níveis possíveis. Quanto ao referencial "Qualidade de Vida", tem-se na variável "Coleta de esgoto precária" a incidência média de 22,6\% das residências e, quanto ao "Acesso precário à água", temos a incidência média de 5\% no bairro São João. Quando se trata do eixo de aspectos que contribuem para o "Desenvolvimento Humano", verifica-se que a média é de 19\% dos "responsáveis pelos domicílios com 1 a 3 anos de estudos". A "taxa de homicídios", no ano de 2005, girou em torno de 41 vítimas para cada 100 mil habitantes, atribuindo o quarto nível em escala de sete no mapa criminal. Somados aos demais indicadores, o Índice de Exclusão Social (IES) do bairro São João gira em torno de $-0,87$, figurando entre os bairros com o pior IES quanto ao desenvolvimento humano no município (SEDAE, 2005). Dados mais recentes do Índice Paulista de Vulnerabilidade Social apontam para uma classificação do bairro São João entre os grupos 3 e 4, dos seis possíveis quanto ao grau de vulnerabilidade, com especial melhora nas áreas do bairro com mais proximidade ao aeroporto (SEDAE, 2013).

\section{A constituição do campo religioso guarulhense - censo 2010}

O primeiro dado a constatar é que há predominância dos católicos, são $53 \%$ da população, depois os evangélicos que são $28 \%$, e os sem religião que já somam $11 \%$ e os espíritas que representam 3\% da população do município. Observa-se que $84 \%$ do quadro religioso guarulhense fica ocupado por tradições religiosas cristãs (catolicismo, evangélicos e espíritas), com uma alta representatividade de pessoas que se declaram não vinculadas a instituições religiosas $(11 \%)$, restando uma parcela de $5 \%$ da população que se identifica como pertencente a outras religiões minoritárias. 
Quando comparados aos dados da média nacional brasileira, onde temos $64,6 \%$ de católicos, $22,2 \%$ de evangélicos, $8 \%$ dos sem religião e $2 \%$ de espíritas, é possível observar que, apesar da consonância de representatividade religiosa hegemônica no município, existe uma menor representatividade católica em Guarulhos do que na média nacional e uma tendência maior de evangélicos, sem religião, e espíritas em Guarulhos que configuram um quadro particular nesse campo.

A seguir, vêm as religiões minoritárias, entre as quais se destacam historicamente as afro-brasileiras, com cerca de $0,4 \%$ da população guarulhense, maior portanto que a média brasileira $(0,35 \%)$. De modo geral, constata-se que a perda de força da hegemonia católica já observada nos últimos censos nacionais se revela mais impactante no município que na média nacional, fato que pode favorecer o trânsito dessas populações para outras religiosidades ou mesmo para a desvinculação de instituições religiosas, figurando em os "sem religião", e de certo modo isso favorece outras religiosidades, incluindo religiões relativamente novas no cenário religioso brasileiro, como é o caso das NRJ.

Convém um olhar específico ao lugar das NRJ, em Guarulhos. Quando se analisa os dados das religiões minoritárias, vê-se que a representatividade do budismo (0,4\%) em Guarulhos, por exemplo, é igual a das tradições afrobrasileiras, sendo que no quadro nacional o budismo representa apenas $0,13 \%$, chamando a atenção o fato de religiões de tamanho peso histórico e social como as afro-brasileiras terem no município a mesma representatividade de uma religião oriental de tão recente chegada.

No município de Guarulhos estão presentes algumas vertentes das NRJ, como a Soka Gakkai, religião tida como predominantemente budista e introduzida no Brasil na década de 1960. Em Guarulhos, sua presença se faz por intermédio de membros que promovem reuniões de culto e divulgação em suas casas, não dispondo de estruturas próprias de igrejas ou templos no município. Segundo o vice coordenador da entidade na capital, Alexandre Kogage, no ano de 2014 a entidade contava com cerca de dois mil membros na macrorregião de Guarulhos (GUARULHOSWEB, 2014).

Consta também no município a presença da Sukyo Mahikari, uma NRJ iniciada no Japão na década de 1950. Essa religião possui como principal atividade no município o atendimento de membros e não membros pela imposição de mãos, chamada de Arte Mahikari ou Okiyome, uma espécie de tratamento de cunho metafísico muito semelhante ao Johrei proposto 
pela Igreja Messiânica. A sede local oferece o curso preparatório para a conversão, mas não oficia a cerimônia que outorga a joia Omitama (pequena medalha com inscrições em japonês) que habilita o novo membro a realizar a imposição de mãos. Em Guarulhos, conta com apenas uma igreja designada Okiyomesho Guarulhos Sukyo Mahikari, localizada na região central da cidade e que visa atender à pequena comunidade de membros locais.

Com maior expressão numérica de membros, a Seicho-No-Ie (SNI) possui uma "Sub Sede Regional" instalada na região central de Guarulhos, sendo responsável pelas filiais nos municípios vizinhos de Arujá e de Santa Isabel, bem como, mais três "Associações Locais" nos bairros do Santa Mena, Vila Rosália e Parque das Nações. Até o ano de 2000, a SNI tinha em sua composição $80 \%$ de adeptos e dois terços do clero formados por não descendentes de japoneses (MENEZES e TEIXEIRA, 2013).

A Tenrikyō conta com duas igrejas ativas no município: a Igreja Brasil Koshihiro, localizada no bairro Jardim São Francisco, e a Igreja São Paulo, situada no bairro do Sadokim, ambas em bairros de periferia. Possui, ainda, com mais três Casas de Divulgação, espaços disponibilizados por membros em suas casas para reuniões dos membros locais, a saber: Casa de Divulgação Shirayuki, no bairro da Vila Augusta, Casa de Divulgação Kasadomaru, no bairro do Santa Mena, e a Casa de Divulgação Paulista III, no bairro do Jardim Cocaia. As igrejas desenvolvem atividades como os cultos mensais, cursos, reuniões das associações feminina e juvenil, bazares e quermesses.

A Igreja Messiânica Mundial, por sua vez, possui um "Centro de Aprimoramento" em Guarulhos, no bairro do Jardim Tranquilidade, que é responsável não apenas pelos outros quatro Johrei Centers do município, localizados nos bairros do Jardim Maia, Jardim São João, Taboão e Vila Rosália, como também por outros da microrregião. Os dados censitários, quanto à categoria "novas religiões orientais", revelam em Guarulhos que $0,2 \%$ da população está ligada a alguma dessas religiões, sendo que desse total $0,14 \%$ são membros da IMMB no município. Quando comparamos aos mesmos números no quadro nacional, observamos que as novas religiões orientais somam 0,09\% da população dos quais a Igreja Messiânica representa 0,02\% do grupo. Dessa maneira, observa-se que a IMM representa uma parcela muito maior de membros das novas religiões orientais no município que no quadro nacional. 


\section{A Igreja Messiânica em Guarulhos}

A história da Igreja Messiânica em Guarulhos recebeu alguns dos primeiros missionários japoneses oficialmente enviados com o objetivo de estabelecimento sistemático e difusão da igreja no país, o Sr. Shoda e o Sr. Nakahashi, sendo que apenas o primeiro acabou permanecendo em Guarulhos. O missionário Shoda, um dos responsáveis pioneiros da igreja no Brasil, estabeleceu-se no início de sua missão em Guarulhos junto à família messiânica Iyama, que o acolheu:

Após sua chegada em solo brasileiro, a despeito de todas as dificuldades, seja de recursos financeiros ou de comunicação, Shoda e Nakahashi se instalaram na cidade de Guarulhos e iniciaram a ministração de Johrei. Com a cura de um taxista (...), cresceu o número de interessados em receber o Johrei com a finalidade de resoluções de problemas de saúde, financeiros e de relacionamento pessoal. (...) Shoda permaneceu em Guarulhos até junho de 1956 ocasião em que seguiria para Curitiba ao encontro de Nakahashi (TOMITA, 2009, p. 57).

Foi assim que começou a Igreja Messiânica do Brasil em Guarulhos, em decorrência dos esforços da família Iyama, que deu prosseguimento aos planos do missionário. O casal Iyama conheceu a igreja devido à doença que acometeu a Sra. Iyama e levados à igreja em busca da cura obtiveram um milagre, segundo relatos, graças ao Johrei. Como gesto de gratidão, a família decidiu retribuir a graça alcançada, primeiro convertendo-se por meio do recebimento do ohikari (medalha para ministração do Johrei), em 1962, e depois iniciando as atividades da igreja em sua própria casa no atual bairro da Tranquilidade, originando assim a difusão pioneira em Guarulhos. Os oito filhos desde tenra idade recebiam igualmente o ohikari para se tornarem aptos a auxiliar no atendimento dos necessitados que buscavam a igreja como alternativa de tratamento de doenças.

Hoje, o espaço que antes era a casa da família Iyama expandiu-se, e se tornou a sede da atual Igreja Guarulhos, antes Centro de Aprimoramento Guarulhos, que ocupa mais três terrenos vizinhos adquiridos para a construção da sede que cresceu desde então e alcançou 56 anos de existência, em 2018, no mesmo local em que fora fundada. O crescimento da igreja no Brasil, vivido nas décadas de 1990 e ainda mais na década de 2000, foi sentido também no município com o surgimento de diversas igrejas em bairros distintos, os Johrei Centers, atualmente em número de quatro, além dos núcleos regionais e de 
divulgação. A sede da Igreja em Guarulhos inclusive passou a administrar não apenas os Johrei Center existentes em Guarulhos, como em toda a macrorregião que engloba os municípios de Guarulhos, Arujá, Poá, Biritiba Mirim, Suzano, Mairiporã e Suzano, na região da grande São Paulo.

Entre os Johrei Centers pertencentes à Igreja Messiânica de Guarulhos, prestamos atenção neste artigo a uma dessas comunidades, o Johrei Center São João, localizado em bairro da periferia do município. A seguir, serão tratados aspectos importantes da dinâmica dessa comunidade em relação ao bairro em que se localiza, ou seja, como o seu histórico e a intencionalidade de estabelecimento nessa região, bem como, aspectos sociais e culturais observados entre seus adeptos.

\section{O Johrei Center São João na periferia de Guarulhos}

No Johrei Center São João, observa-se uma história de mudanças de sede e adoção dos nomes dos bairros nos quais se estabeleceu ao longo dessas mudanças. Originalmente, nasceu cerca de 20 anos atrás como Johrei Center Vila Fátima, permanecendo nesse bairro por quase dez anos. Com o advento do término do contrato de locação, nasceu a possibilidade de levar-se em consideração a necessidade de mudança para um bairro mais próximo da maioria dos membros que se deslocavam até lá e, atendendo ao orçamento estabelecido para locação, surgiu a oportunidade de mudar-se para a região do Parque Cumbica, já mais próximo da sede atual, fronteiriço à região das indústrias do entorno do Aeroporto de Guarulhos. Nesse local, permaneceram por cerca de cinco anos, e o grupo de membros teve pouco crescimento na região, quando decidiram mudar-se mais uma vez, agora para a região do São João, um bairro mais distante do centro e mais carente que o anterior, todavia, mais próximo dos membros frequentadores.

Aqui, segundo os adeptos, a igreja viu crescer o número de aderentes, especialmente entre os moradores, não apenas do bairro São João, mas de todos os bairros do entorno. A opção desse local surgiu graças à ponderação por parte da comunidade das novas obras em transporte que passaram a melhor atender à região, como o terminal de ônibus do São João e a futura linha da CPTM, que prometia facilitar o acesso ao bairro. Ainda foi levado em consideração o valor de locação do imóvel para ser a sede do Johrei Center (JC), que é consideravelmente mais barato na região que nos bairros adjacentes ao centro. 
Após cinco anos nessa casa, os membros já demonstravam interesse em mudar-se para um local maior, porém ainda na região. Esse Johrei Center conta, ainda, com células de difusão locais que funcionam com reuniões semanais de culto e ministração de Johrei, que ocorrem habitualmente na casa dos membros. Essas são três comunidades chamadas "Núcleos de Johrei" que estão, respectivamente, nos bairros próximos do Santos Dumont, do Bonsucesso e um Núcleo chamado Aeroporto, que ocorre dentro da capela ecumênica do Aeroporto de Guarulhos. A presença na capela do aeroporto foi estrategicamente pensada pelo grande trânsito de pessoas e fazer-se necessário reafirmar, nesse espaço, a religião messiânica como parte das religiões brasileiras. Nessa capela, pertencente ao aeroporto, ocorrem cultos de mais diversas religiões que ocupam, mediante agendamento, um período de um dos dias da semana para a realização de suas atividades e divulgação junto aos passageiros.

O JC São João parece nutrir uma preocupação em difusão da igreja no bairro em que se estabeleceu, desempenhando atividades constantes de divulgação nas ruas, por meio da distribuição dos chamados "minibana" (pequeno arranjo floral) de modo a, junto desse atrativo, convidar as pessoas para "receberem uma oração na igreja", ${ }^{3}$ ou seja, uma ministração de Johrei, além de desenvolverem mensalmente atividades em uma praça próxima como: horta comunitária; o ensino da agricultura natural; eventos de Ikebana e; limpeza das ruas do entorno no bairro em agradecimento.

Apesar dos fatores financeiros e, novamente, da especulação imobiliária tornarem muito caros os preços de locação dos imóveis mais centrais, fato que contribui pela escolha do bairro, os membros do Johrei Center São João demonstram consciência dos benefícios de crescimento do grupo, decorrente da opção pelo estabelecimento nesse bairro, e parecem ter um forte engajamento e interação com a comunidade local. Em verdade, já estavam previamente estabelecidos na região, e a opção pelo São João visou melhor atender aos interesses desses membros que eram moradores dos bairros da região.

\footnotetext{
A adoção da expressão "receber uma oração" como forma de convite aos transeuntes para entrarem na igreja e receberem a ministração de Johrei foi percebida no Johrei Center São João, e parece uma estratégia que diminui o possível impacto ruim naqueles de origem evangélica, tão mais frequentes no bairro, acostumados a receber esse tipo de convite na porta de igrejas cristãs, mas desacostumados com o Johrei que requer a "imposição de mãos", muitas vezes confundido com o passe espírita.
} 


\section{Perfil socioeconômico dos membros do JC São João}

Após essa breve apresentação da comunidade, serão expostos alguns dados que revelam os aspectos sociais, culturais e religiosos dos membros que compõem essa comunidade messiânica da periferia de Guarulhos. Quanto à representatividade por gênero, nota-se uma maior participação feminina, sendo a amostra constituída de 70\% de mulheres no JC São João. Ao observar-se os dados obtidos, é possível notar uma maior frequência de pessoas que afirmam sobreviver com 1 a 2 salários mínimos mensais $(70 \%)$, sendo que outros $20 \%$ declaram viver com 3 a 4 salários mínimos e 10\% afirmam viver com até 1 salário mínimo, sendo que entre os participantes nenhum deles afirmou viver com 5 a 6 salários.

Tabela dos dados de renda e gênero no JC São João, Guarulhos, SP.

\begin{tabular}{|c|c|c|}
\hline & Masculino & Feminino \\
\hline Sem Renda & $0,0 \%$ & $0,0 \%$ \\
\hline$<1$ SM & $0,0 \%$ & $14,28 \%$ \\
\hline 1 a 2 SM & $100,0 \%$ & $57,15 \%$ \\
\hline 3 a 4 SM & $0,0 \%$ & $28,57 \%$ \\
\hline 5 a 6 SM & $0,0 \%$ & $0,0 \%$ \\
\hline Total & $100 \%$ & $100 \%$ \\
\hline
\end{tabular}

Quando confrontamos os dados de gênero aos obtidos na categoria de renda familiar, na amostra do JC São João, um dos bairros mais vulneráveis da periferia de Guarulhos, observa-se uma prevalência daqueles que declaram sobreviver com renda na faixa de 1 a 2 salários mínimos (SM), respectivamente, $57,15 \%$ das mulheres e $100 \%$ dos homens participantes. Não existem declarantes que não possuam renda familiar, mas cerca de 14\% dos questionados afirmam viver com menos de 1 salário mínimo, sendo o teto de renda dos participantes de 3 a 4 salários mínimos.

Ao analisar a faixa etária dos membros, é possível notar que a maioria deles se distribui entre as faixas etárias de 26 a 45 anos (40\%) e as faixas etárias de 51 a 70 anos (40\%), com menor prevalência de representantes da faixa etária de jovens entre 18 e 25 anos (10\%) e de idosos entre 71 a 80 anos $(10 \%)$, apresentando, portanto, uma distribuição etária relativamente equilibrada entre adultos. Os jovens, que representam parte do grupo de 
vulnerabilidade, estão pouco representados entre as fileiras messiânicas na periferia de Guarulhos, de modo geral.

Ao avaliar o número de pessoas que moram junto do participante da pesquisa, nota-se a prevalência daqueles que moram com uma a três pessoas (80\%). Quando confrontado esse dado com os apresentados na renda familiar prevalente, de 1 a 2 salários mínimos, é possível notar um agravamento no quesito renda desses participantes. Quanto ao "estado civil" dos membros, é possível observar que são equivalentes tanto na representação dos "casados" (40\%) como dos "solteiros" (40\%, seguidos de $20 \%$ daqueles que se declaram viúvos. Parece natural em uma população mais madura uma representação significativa de casados e mesmo de viúvos. Não há representante das categorias divorciados e outros estados civis. Vale lembrar que, além de denunciar os valores morais mais rígidos, o enlace conjugal tem um importante valor simbólico no espaço da periferia, onde muitos lares contam apenas com mulheres como chefes de família.

Já na avaliação de composição por raça ou cor, observa-se que, no JC São João, a população de brancos é de $50 \%$ dos declarantes e que a categoria negros e pardos representa 40\%, sendo que apenas $10 \%$ se declaram amarelos. Os dados evidenciam a menor presença de nipo-descendentes na composição da filiação desses grupos e uma porção ligeiramente maior de declarantes brancos entre as fileiras que de negros e pardos.

Os dados de escolaridade revelam que nesse JC, cerca de $60 \%$ dos membros afirmam que estudaram até o Ensino Fundamental, e destes, a grande maioria $(40 \%)$ declara que estudaram apenas até a antiga $4^{a}$ série. Os demais (40\%) afirmam ter atingido o antigo Ensino Médio, sendo que ninguém declarou ter concluído os estudos de nível superior, e esse baixo nível de escolaridade dos membros pode ser um fator de reforço da vulnerabilidade da renda já observada.

Quando se cruzam os dados de escolaridade e renda na população geral de participantes, nota-se que a maioria dos membros desse JC afirma que estudaram até a $4^{a}$ série do Ensino Fundamental e vivem com uma renda familiar de 1 a 2 salários mínimos, seguidos daqueles que estudaram até o Ensino Médio e alegam viver com essa mesma renda (20\%) ou, ainda, os que declaram a conclusão dos estudos até o Ensino Médio, mas que vivem com uma renda familiar mensal de 3 a 4 salários mínimos. Esse fator revela que a escolaridade é de grande influência na renda, mas outros fatores do lugar 
concorrem para o acesso à oportunidades de mobilidade social e reafirmam a maior vulnerabilidade vivida no bairro São João e região.

Quanto ao fator migração, nota-se que a maioria dos membros do JC São João (80\%) afirma residir na cidade de Guarulhos há mais de 20 anos, mas muitos destes $(80 \%)$ não são nascidos no município e sim migraram para ele. O que, de modo geral, os dados revelam é que as condições sociais e econômicas dos moradores do bairro e região, onde está localizada a igreja estudada, são predominantemente as mesmas dos membros do JC em questão.

\section{Contribuições dos Johrei Centers ao bairro}

Além dos fatores socioeconômicos, observou-se nessa comunidade seus hábitos, produções de sentido e possíveis funções seculares desempenhadas no âmbito religioso. Começamos pela visão que os membros possuem das contribuições dadas pela presença de sua igreja ao bairro em que se localizam. Para tal avaliação, foram oferecidas algumas categorias de contribuições estabelecidas após a observação participativa de ordem: "econômica", "cultural", "social", "espiritual", “não sei", “outra”. Os membros poderiam escolher mais de uma categoria, concomitantemente, de modo a não restringir o número de contribuições percebidas pelo adepto.

Todos os membros afirmaram que o Johrei Center contribui espiritualmente com o bairro, evidenciando a importância da dimensão simbólica que a religião ocupa. Muitos, ao tratar dessa categoria, comentavam que o Johrei Center traz "força espiritual para a vizinhança", "esperança para as pessoas do bairro", além de justificarem que a igreja funciona como um "local de propagação da luz espiritual".

A segunda contribuição mais mencionada entre os membros é a contribuição social dada pela presença do Johrei Center no bairro, sendo essa categoria mencionada por 40\% dos membros. Os comentários acerca dessas contribuições justificam que o Johrei Center oferece atividades sociais, como bazares e festas abertas à comunidade. Os membros justificaram que o trabalho com os jovens é muito valorizado nessa igreja, além de oferecerem oficinas de horta natural esporadicamente em uma praça próxima da igreja, onde também são oferecidas vivências de arranjo floral. Outra atividade associada pelos membros a essa categoria é a limpeza de agradecimento mensal realizada nas ruas e praças do bairro periodicamente. A terceira contribuição mais citada é a cultural, assinalada por $10 \%$ dos membros e, 
mais uma vez, as atividades como promoção de festas, bazares e vivências de arranjo floral (Ikebana) são associadas a essa categoria.

Não houve respostas que assinalam a percepção de contribuições de ordem econômica ou na categoria "não sei". É comum os membros destacarem que a Igreja Messiânica enfatiza a educação de seus adeptos para a resolução de seus problemas pessoais a partir da compreensão da doutrina espiritual, incluindo os de ordem social, econômica e financeira, não enfatizando trabalhos caritativos ou beneficentes. Contudo, não foi encontrada nessa comunidade qualquer atividade educativa que vise, diretamente, algum tipo de aprendizado com objetivo de promover inserção ou promoção da ordem socioeconômica.

É claro que os benefícios advindos de se associar a uma comunidade religiosa na periferia não se restringem àqueles propostos racionalmente pelas instituições religiosas, uma vez que as oportunidades de inserção dadas nas relações dentro da comunidade extrapolam esses limites. Especialmente na modernidade, e compartilhando as NRJ de características dos Novos Movimentos Religiosos, diminui-se a resistência tanto do indivíduo quanto da instituição em assumir e lidar com os ganhos secundários da conversão.

\section{Práticas dos membros messiânicos no bairro São João}

Visando à melhor compreensão das dinâmicas envolvidas nas práticas que são desempenhadas dentro de um Johrei Center, é importante compreender a rotina de atividades ali desenvolvidas. É concomitante às práticas oficiais, ou seja, previstas institucionalmente e com objetivos ligados diretamente àqueles de uma instituição religiosa, que notamos ocorrer outras que serão chamadas aqui de "funções inovadoras" por atenderem às demandas seculares resolvidas, completa ou parcialmente, dentro do contexto religioso. Estas se revelam, em verdade, estratégias de compensação de parte das carências vividas nessa região de periferia urbana.

Uma série de atividades corriqueiras é desempenhada em um Johrei Center como: culto diário matutino, culto diário vesperal, plantões de ministração e recebimento de Johrei, cultos mensais de agradecimento, cultos mensais no Solo Sagrado de Guarapiranga, limpeza de agradecimento do bairro, distribuição de mini arranjos florais à comunidade externa, atividades com os jovens, aconselhamento com os ministros, e visitas de comissões às famílias em suas residências. Como afirma Pereira (2004), as estratégias padronizadas, que lembram as adotadas por empresas multinacionais, parecem 
permitir pouca inovação no que diz respeito à programação de um Johrei Center, advindo daí a opção de intitular aqui essas atividades, previstas pela sede central da igreja, como corriqueiras.

Essas atividades, comuns ao calendário anual de qualquer Johrei Center, são desempenhadas em ciclos semanais e mensais. Outras atividades são desempenhadas dentro de um Johrei Center, mas dependem ou da sazonalidade do calendário litúrgico anual ou da demanda como cultos aos ancestrais, sagração de medalhas de Johrei (ohikari), oficinas de Ikebana, oficinas de agricultura natural, palestras abertas, treinamentos aos voluntários e aulas de doutrina, que visam à preparação para o seminário de outorga da medalha de Johrei (ohikari), para citar alguns.

De modo geral, o JC desempenha essas atividades corriqueiras e funciona com uma periodicidade semanal, de domingo a domingo, alternando apenas os horários de funcionamento, sendo que as atividades de segunda a sábado são realizadas das 8 horas às 20 horas e, aos domingos, o funcionamento se limita ao período das 8 horas às 13 horas.

No JC, o ministro responsável é do tipo "dedicante", ou seja, não é funcionário da igreja mantendo uma vida secular (trabalho e família) concomitante, o que limita a participação do mesmo em até algumas horas semanais que, ou são distribuídas em poucas horas todos os dias da semana ou se concentram em muitas horas de trabalho na igreja alguns dos dias da semana. Os plantões diários de ministração e recebimento de Johrei ocorrem por turnos: matutino, vespertino e noturno, e dependem dos membros voluntários que tenham disponibilidade ao longo da semana para manter essa rotina. A doação de horas aos serviços da igreja é vista como parte da prática espiritual e ocorre de modo variado de acordo com a disponibilidade de tempo de cada membro. Ao longo da pesquisa, foram observados hábitos de frequência que variam tanto de jovens que, por trabalharem durante a semana, dedicam apenas 30 minutos do seu horário de almoço uma vez na semana para ministrar Johrei e recebê-lo, até membros que já são aposentados e se voluntariam em mais de dois dias nos plantões semanais no Johrei Center. Essa prática, de ministração e recebimento de Johrei, é a que mais ocupa horas de atividade dentro de um Johrei Center, revelando mais uma vez a centralidade do processo de cura física e espiritual simbolizada no Johrei.

De modo geral, o fluxo de pessoas visitantes e membros aumenta consideravelmente, uma vez ao mês, no Culto de Agradecimento Mensal, que ocorre sempre no final de semana seguinte ao Culto Mensal no Solo 
Sagrado de Guarapiranga, normalmente aos domingos, e que demanda uma caravana até a sede. O Johrei Center São João parece desempenhar muitas atividades externas, como a divulgação nas proximidades do bairro (por meio da distribuição de mini arranjos florais, oficinas que promovem o Ikebana e a agricultura natural em uma praça próxima do Johrei Center) e a limpeza das ruas e praças públicas do entorno da igreja como gratidão, que não foram observadas em outros Johrei Centers da periferia de Guarulhos. Provavelmente, essa diferença possa ser relacionada ao envolvimento e número de jovens maior nas atividades desse JC, que possui uma população mais expressiva de jovens adultos, de 18 a 44 anos de idade, cerca de 50\%, que em outros onde a faixa etária é mais velha.

Ao serem questionados quanto à frequência semanal na igreja, os declarantes afirmam ir até o Johrei Center mais de três vezes por semana (70\%), uma frequência relativamente mais alta que em outros JC estudados na periferia. Estando em uma região mais vulnerável da periferia de Guarulhos, a maior taxa de frequência pode representar uma maior busca dos membros de satisfazer as necessidades de sociabilidade, de partilhar angústias do processo de adoecimento, inserção social, e sociabilidade.

Quando questionados acerca do número de atividades que costumam desempenhar na igreja, os dados são difusos entre a maioria, que afirma participar em ao menos seis atividades na igreja (40\%), seguido de $20 \%$, que declaram participar de quatro atividades, e aqueles que afirmam participar entre duas, cinco, sete ou oito atividades, $10 \%$ da população em cada uma dessas categorias. Ao serem questionados quanto à natureza das atividades desempenhadas, foram oferecidas as categorias de atividades mais frequentes como resposta, a saber: "Recebo Johrei", "Dedico nos plantões", "Ministro o Johrei", "Culto Matutino", "Culto Vesperal”, "Culto de Agradecimento Mensal", "Culto no Solo Sagrado de Guarapiranga", "Ikebana”, além da categoria "outras" onde era possível acrescentar alguma não citada. Em primeiro lugar, aparecem as respostas "Recebo Johrei" e "Ministro Johrei", com 100\% de respostas, seguida de participação no "Culto de Agradecimento Mensal", com 92\% de representatividade e, em terceiro lugar, o envolvimento por meio da dedicação em plantões, com $88 \%$ de respostas. Detendo uma população menos idosa, esse Johrei Center revela mais envolvimento na atividade central da igreja, o Johrei, seguida dos plantões, que os cultos propriamente ditos. Isso mostra como o processo de conversão se dá 
pela demanda da igreja na participação do membro mais no cotidiano da comunidade local (plantões) do que nos cultos propriamente ditos.

Muitos dos membros e dos visitantes que procuram a igreja por estarem em um período de crise em suas vidas (doença, desemprego, conflitos) são orientados a repetir um número de horas de recebimento de Johrei diário. Assim, é possível notar que algumas dessas pessoas frequentam o espaço para essa espécie de "tratamento espiritual" intensivo ao longo dos dias da semana.

\section{Conversão e identidade com o grupo religioso na periferia}

Refletimos nesta parte sobre as motivações que levaram os participantes a se converter oficialmente à igreja. Conversão, nesse caso, significa passar pelo seminário de preparação e respectiva cerimônia de outorga da medalha para ministração de johrei, bem como, a motivação de permanência na igreja até o momento da pesquisa. Também visa-se, nesta parte, esclarecer a motivação de adesão à nova identidade religiosa, isto é, de iniciar e persistir na travessia da uma identidade religiosa de origem rumo à identidade religiosa de destino.

Foram oferecidas oito categorias de respostas: "busca por autoaperfeiçoamento"; "busca por entender a doutrina e leis espirituais"; "busca por resolução de problemas cotidianos"; "busca por resolução de problemas de saúde"; "busca por resolução de problemas familiares"; "busca por resolução de problemas financeiros"; "busca por atividades que ocupassem seu tempo livre"; "busca por companhia"; além da opção "outros", onde o participante poderia incluir uma motivação não dada. Cada categoria poderia ser ou não assinalada pelo indivíduo como parte de sua motivação.

As respostas mais frequentes para conversão são a busca por compreender a doutrina espiritual $(30 \%)$ e a resolução de problemas de saúde $(30 \%)$, seguida pela busca por companhia e amizades, portanto, por socialização (20\%), busca de resolução dos problemas cotidianos $(20 \%)$, busca por resolução de problemas familiares e afetivos $(20 \%)$ e "outros" (20\%). Uma diversidade de intenção parece mais distribuída que nas motivações, o que leva a crer que em áreas mais vulneráveis, como no bairro São João, as motivações se distanciem mais das funções oficialmente designadas à igreja e se aproximem mais da compensação de carências vividas no cotidiano.

Ao se questionar as motivações da permanência na igreja, foram ofertadas as mesmas respostas da categoria "motivo de conversão", sendo que, novamente, poderiam optar por mais de um motivo. As respostas mais 
comuns para a motivação de permanência entre os membros participantes foram as assinaladas na opção "outros motivos", que se dividem entre os que afirmam "serem gratos à igreja por graças recebidas" e outros que declaram "se sentirem bem na igreja" (40\%). Em segundo lugar, aparecem empatadas as categorias: "autoaperfeiçoamento"; a "busca por aprender a doutrina espiritual" e; a "busca por resolução de problemas cotidianos", todos com 30\% de ocorrência. Em terceiro lugar, está a categoria "busca por resolução e orientação para solucionar problemas familiares e cotidianos" $(20 \%)$. Aqui por meio da categoria "outros" os membros relacionam seu motivo de permanência ou à retribuição dos benefícios obtidos por adesão a igreja ou à liberdade encontrada na doutrina e na comunidade que os fazem sentir-se bem em participarem. Parecem fatores importantes na construção da identidade messiânica o quesito "liberdade", bem como, a ênfase dada aos milagres (saúde, espiritual, familiar) que persiste entre os membros.

Outra das questões feitas aos participantes, visando compreender o fluxo de trânsito religioso nessa comunidade, diz respeito à religião de origem do sujeito. Nessa categoria, foram ofertadas as possibilidades de acordo com o censo (católicos, evangélicos, kardecistas), igualmente a categoria "sempre fui messiânico" destinada àqueles que, porventura, sejam de famílias messiânicas e sejam membros da igreja desde a infância, bem como, a categoria "outra religião", onde poderiam informar qualquer minoria que pertencessem.

$\mathrm{Na}$ amostra, a resposta mais frequente, quanto ao trânsito religioso, revela que 50\% dos participantes eram católicos, 20\% dos demais se dividem entre evangélicos e "outras religiões", 10\% eram kardecistas. Quando comparamos com o quadro brasileiro apresentado pelo Censo 2010, vemos que as respostas seguem a tendência nacional de predominância de católicos, mas o segundo lugar é de modo diferente dividido entre os evangélicos e os membros de "outras religiões", seguindo, no terceiro lugar, entre os espíritas kardecistas. Destaca-se a declaração de $20 \%$ dos membros entrevistados na categoria "outras religiões" e a inexistência de declarantes que tenham nascido em "berço messiânico" entre os entrevistados.

Outra questão apresentada aos participantes foi quanto à "semelhança" ou "diferença" que percebem entre a sua religião de origem e a religião messiânica, sendo que 70\% dos membros do JC afirmam perceberem diferenças entre as religiões. Quando questionados em relação à dificuldade encontrada pelos membros no processo de conversão, na adaptação às diferenças religiosas encontradas em relação a sua religião de origem e no aprendizado dos novos 
conceitos messiânicos, inéditos ao converso, observa-se que apenas $40 \%$ dos participantes declaram que não encontraram dificuldades durante o processo de conversão, sendo que todos os $60 \%$ restantes afirmam que encontraram pouca ou muita dificuldade no processo de conversão.

Os participantes foram inqueridos ainda sobre a necessidade de abandonarem conceitos de suas religiões anteriores como prerrogativa de conversão à Igreja Messiânica. Nenhum dos membros afirmou ter que abandonar conceitos da religião anterior e, no entanto, quando questionados se os conceitos da religião anterior foram acrescentados aos aprendidos na Igreja Messiânica, surpreendentemente se nota que todos os participantes do JC afirmam que sim. Isso demonstra que o conceito de realizar uma leitura messiânica das grandes religiões soma-se à flexibilidade dos membros na busca de composição de suas identidades, justapondo conceitos das doutrinas das religiões típicas do cenário brasileiro seguindo parâmetros sincréticos. É importante destacar que a acomodação de conceitos doutrinários das grandes religiões é uma característica forte nas NRJ no Japão e esse indicador pode sinalizar que o mesmo processo ocorre no Brasil, contribuindo para a construção dessa nova identidade religiosa no membro convertido.

\section{As funções inovadoras dos Johrei Centers na periferia}

No contexto da periferia, as vulnerabilidades que os moradores sofrem os leva a produzir ricas e criativas alternativas que visam minimizar os impactos dessas condições de existência. No contexto religioso moderno, a religião também é um espaço de produções de soluções a dilemas até então seculares. O entendimento do funcionamento de um Johrei Center, como já apresentado, é fundamental para a compreensão dessas consequentes funções inovadoras, por serem seculares no espaço religioso, que ali se desenvolvem e, em grande medida, escapam às intenções institucionais da igreja.

Para avaliar o que chamamos de "funções inovadoras", foram utilizadas seis categorias: a busca por socialização; busca por pertencimento; busca por autoestima; busca por prestígio; a busca por cura física, psíquica e espiritual e; até mesmo a busca por reinserção social. Essas práticas seculares acontecem por intermédio de redes religiosas e de associativismo, e podem muito bem serem definidas como produtoras de bens materiais e simbólicos de determinada religião (NORONHA, 2016).

O que essas funções parecem revelar é que o Johrei Center ocupa um espaço simbólico muito importante na superação de carências, por exemplo, 
no trato com a falta de atendimento público de saúde adequado. A grande maioria dos membros afirma buscar a IMM como saída aos problemas de saúde até então insolúveis, ou seja, que não tiveram suficiente resolução junto aos aparelhos públicos de saúde. Nota-se que a carência de atendimento no sistema público também se estende à falta de um suporte psicológico ao longo do processo de adoecimento e tratamento, muitas vezes invasivo, e que esse adoecer, com frequência, encontra espaço de discussão no Johrei Center ao longo do tratamento espiritual.

Graças à centralidade do processo saúde-doença na Igreja Messiânica, existe um espaço de atividades muito grande destinado a receber a cura espiritual e falar sobre seus problemas de saúde de um modo inédito. Ali o doente encontra pessoas interessadas em sua história e dispostas a ouvir as angústias que circundam o adoecimento, as dores e os limites do tratamento, isto é, um espaço de promoção do processo que a psicologia denomina elaboração psicológica do adoecer. Esse ambiente de acolhimento e elaboração subjetiva é ainda menos usual no espaço da periferia, onde o tratamento do aspecto somático já é negligenciado em postos de saúde e hospitais públicos, que deixam muito a desejar em eficiência. O espaço adequado inexistente na saúde pública, visando tratar dos aspectos emocionais do adoecer com um psicólogo hospitalar (em grupos funcionais, por exemplo), parece realizado em parte na comunidade religiosa.

A busca por socialização é outro fator de grande importância, pois, tanto os mais velhos como os mais novos membros encontram nas atividades desenvolvidas no Johrei Center formas de se socializar e até mesmo de lazer. Entre os mais velhos, nota-se que muitos procuram socializar-se por meio do envolvimento no trabalho voluntário dos plantões de funcionamento do Johrei Center, encontrando, entre uma tarefa e outra, a oportunidade de conversa e lazer em atividades como o Ikebana e o cultivo de hortas naturais ou dos jardins da igreja.

Esse tipo de ocupação é essencial ao idoso, uma vez que desenvolve suas habilidades, ajudando no convívio das relações com o meio e, em muitos dos casos, fortalece seus recursos internos, possibilitando a criação de laços de amizade e aumento da autoestima. Dessa maneira, o idoso fortalece recursos sociais e emocionais para enfrentamento dos desafios impostos pelo envelhecer, adaptando-se com maior facilidade e qualidade de vida. A ocupação possibilitada ao idoso é essencial, pois: "constitui-se num estímulo e razão da vida; auxilia na realização de planos, favorece contatos 
sociais, fortalece a participação em comunidades e possibilita a realização de exercício da sua cidadania” (RODRIGO, 2009, p. 41). A população mais idosa presente no Johrei Center é recorrente em afirmar a função de ocupação que a comunidade representa e a sensação de ser útil após a aposentadoria, destacando-se entre os que mais horas se dedicam como voluntários nas funções semanais da igreja.

O Johrei Center, como reprodução local da instituição, exige que a comunidade ocupe uma série de cargos e funções a serem desempenhadas para o seu funcionamento. As atividades diárias, de domingo a domingo, dependem de escalas de voluntários para o seu cumprimento. A inserção dos membros nessas funções é atribuída tanto pela confiança diante dos dirigentes quanto pela dedicação e disponibilidade do membro à comunidade. Ocupar determinadas funções, incluindo aquelas de ministro dedicante, depende em grande parte do comprometimento prévio e indicação dos superiores na hierarquia da igreja. Normalmente, aqueles que ocupam determinada função hierárquica mais alta desfrutam de maior respeito e prestígio ante a comunidade pela responsabilidade inerente à sua função, apesar de ser esperado de todos o mínimo de envolvimento como em atividades mais simples, como ministrar e receber Johrei semanalmente.

Com menor frequência nos relatos, a questão da reinserção social também aparece por intermédio de membros que afirmam terem abandonado o vício em drogas lícitas e ilícitas graças à inserção na comunidade religiosa que os acolheu. Isso pode ser demonstrado pelo depoimento de um membro que declara ter recebido um milagre de recuperação de sua saúde física e ter abandonado sua vida junto ao crime organizado graças ao acolhimento na Igreja Messiânica.

\section{Considerações finais}

A temática das "Novas Religiões Japonesas" guarda ainda muitas possibilidades a serem exploradas em diversas áreas de estudos como as ciências sociais, ciências da religião, antropologia e história. Essas religiosidades orientais vêm ganhando destaque entre as minorias religiosas brasileiras, alcançando números de membros comparáveis às tradicionais religiões afro-brasileiras, fato que chama a atenção. A incursão aqui proposta, de analisar um aspecto dessas religiões orientais especificamente na periferia urbana de uma grande cidade brasileira, como em Guarulhos, SP, é um 
exemplo de temática quase não explorada academicamente e que possui muito potencial. Como discutido ao longo do texto, a religião é um lugar privilegiado de estudo das dinâmicas sociais e do processo de urbanização tão exacerbados nas periferias. As soluções criativas, ante tamanha vulnerabilidade observada nos bairros menos aparelhados, são encontradas inclusive no contexto religioso, como soluções alternativas locais a problemas não resolvidos pelo poder público, e muitas vezes extrapolando a intencionalidade da instituição religiosa.

A Igreja Messiânica, como algumas das NRJ, conseguiu com eficiência vencer a barreira étnica, passando por um processo de abrasileiramento de sucesso a ponto de encontrarmos representações em bairros de periferia onde se confirma sua composição por membros não nipo-descendentes. A igreja não parece propor intervenções mais diretas de ordem social e econômica na vida de seus membros, mas, como discutido nas "contribuições da igreja ao bairro", afirma-se ser a contribuição mais de ordem espiritual e cultural.

Observou-se que as mesmas "funções criativas" desempenhadas no contexto religioso evangélico, por exemplo, presente nas periferias, também ocorrem, à sua maneira, no contexto de uma Nova Religião Japonesa instalada em bairros de maior vulnerabilidade. O espaço religioso se reafirma como contribuinte na inserção de seus membros a novas oportunidades, atendendo não apenas ao aspecto simbólico, mas igualmente à socialização em um grupo composto por outros membros que partilham das mesmas carências, anseios e opiniões sobre a realidade vivida nessas regiões. Entretanto, o não envolvimento em outros tipos de associação de engajamento social revela que o espaço religioso pode reforçar, em alguns aspectos, a homofilia, ${ }^{4}$ sendo que as igrejas poderiam estimular a participação dos membros em outras esferas da sociedade, de modo a não manter a atuação e inserção social de seus membros em níveis meramente potenciais e locais, tendo acesso apenas a algum nível de empoderamento e prestígio, que não necessariamente se refletirá em melhorias em suas condições financeiras, como já revelado por outros autores ao estudar religiões em periferia urbana (NORONHA, 2016).

Percebe-se, finalmente, que o tom e o ritmo das mudanças dadas pelos fiéis e práticas locais, quando recebidos e reflexivamente filtrados pela instituição, constituem valiosos elementos na construção da identidade

4 Por homofilia entende-se a tendência a restringir, por conveniência ou por familiaridade, as relações sociais apenas entre pessoas que se encontram em semelhantes condições de existência, reduzindo o contato do grupo com os considerados diferentes. 
religiosa local, que não apenas garantirá a sobrevivência da religião transnacionalizada como uma minoria sustentável, mas igualmente possui o potencial de se tornar socialmente relevante na construção de mudanças, no empoderamento dos indivíduos e no estímulo ao engajamento destes nos problemas temporais locais.

\section{Referências}

CAMPOS FILHO, Cândido Malta. Cidades brasileiras: seu controle ou o caos: o que os cidadãos devem fazer para a humanização das cidades no Brasil. São Paulo: Nobel, 1989.

CASTELLS, Manuel. A questão urbana. São Paulo: Paz e terra, 1983.

GAMA, Nilton Oliveira. O Processo de Conformação da Periferia Urbana do Município de Guarulhos: Os Loteamentos Periféricos como (Re)produção de Novas Espacialidades e Lugar de Reprodução de Força de Trabalho. Dissertação de Mestrado, 2009. Faculdade de Filosofia Letras e Ciências Humanas da Universidade de São Paulo, São Paulo, 2009.

MENEZES, Renata; TEIXEIRA, Faustino. Religiões em movimento: o censo de 2010. Petrópolis: Vozes, 2013.

NERI, Marcelo (2011). Novo mapa das religiões. Disponível em: <http://www.fgv.br/cps/ religiao/>. Acesso em 22 dez. 2017.

NORONHA, Claudio Pereira. Trocas materiais e simbólicas em Rio Grande da Serra: redes sóciorreligiosas na periferia urbana. Curitiba: CRV, 2016.

RENNÓ, R. L. "Estruturas de oportunidade política e engajamento em organizações da sociedade civil: um estudo comparado sobre a américa latina.” In: Rev. Sociol. Polít. Curitiba, 21, p. 71-82, nov. 2003.

RIVERA, Dario Paulo Barrera (Org.). Diversidade religiosa e laicidade no mundo urbano Latino-Americano. Curitiba: Editora CRV, 2016.

RODRIGO, Rosimeire C. B. Significado das oficinas de ocupação para idosos com deficiência intelectual. Dissertação de mestrado, PUC-SP, 2009.

ROMÃO, Renan. A Igreja Messiânica na periferia urbana de Guarulhos, SP: um estudo sobre as práticas, identidade religiosa, marginalidade e corte em uma Nova Religião Japonesa. São Paulo, Dissertação em Ciências da Religião, UMESP, 2018.

TOMITA, Andréa Gomes Santiago. Recomposições identitárias na integração religiosa e cultural da Igreja Messiânica no Brasil. Tese (Doutorado em Ciências da Religião) - Universidade Metodista de São Paulo, São Bernardo do Campo, 2009. 


\section{Documentos oficiais}

Censos demográficos de 2010, IBGE.

PLHIS de Guarulhos - Diagnóstico do Setor Habitacional, Prefeitura Municipal de Guarulhos, Secretaria de Habitação, 2011.

GUARULHOS, Relatório de Gestão do Município 2012, Prefeitura de Guarulhos, março de 2013.

SEADE. Índice Paulista de Vulnerabilidade Social - IPVS, 2010.

\section{Jornais e revistas}

GUARULHOSWEB, 2014. Entidade budista é homenageada em evento na Câmara. Guarulhosweb, Guarulhos, 3 de novembro de 2014.

Submetido em: 20-11-2018

Aceito em: 25-11-2018 